\title{
Influence of Fine Content and Water Content on the Permanent Mechanical Behavior of a Granular Material Used in Low Traffic Pavements
}

\author{
Peng Jing ${ }^{1}$; Hossein Nowamooz ${ }^{2}$; and Cyrille Chazallon ${ }^{3}$ \\ ${ }^{1} \mathrm{Ph} . D$. Student, Laboratory of Design Engineering, INSA de Strasbourg, 24 Blvd. de la Victoire, 67084 \\ Strasbourg Cedex, France. E-mail: peng.jing@insa-strasbourg.fr \\ ${ }^{2}$ Associate Professor, Laboratory of Design Engineering, INSA de Strasbourg, 24 Blvd. de la Victoire, \\ 67084 Strasbourg Cedex, France. E-mail: hossein.nowamooz@insa-strasbourg.fr \\ ${ }^{3}$ Professor, Laboratory of Design Engineering, INSA de Strasbourg, 24 Blvd. de la Victoire, 67084 \\ Strasbourg Cedex, France. E-mail: cyrille.chazallon@insa-strasbourg.fr
}

\begin{abstract}
Granular materials are usually used in low traffic pavement structures as base layer or sub-base layer. The influence of the fine content on mechanical behavior is significant as well as the water content. In this study, based on the test results, a proposed empirical-analytical model was used to determine the permanent axial deformations of Missillac sand in Repeated Load Triaxial Tests (RLTTs). The model was also used to simulate the other experimental results existing in the literature. Globally, the results show a good capacity of model to estimate the permanent deformation behavior of granular materials.
\end{abstract}

\section{INTRODUCTION}

In low traffic pavements with a thin bituminous surfacing, granular base and subbase layers, permanent deformations of the unbound layers and of the soil represent the main causes of distress that lead to rutting of the pavement surface. Granular materials are commonly used in low traffic pavement structures as base layer or subbase layer which are made of crushed rocks, crushed natural gravels or sands with a certain amount of fines (typically $4 \%$ to $10 \%$ ) or recycled materials.

The permanent deformation behavior (long term behavior) has been studied by many researchers. Various studies have shown the significant influence of the water content and the fine content on mechanical behavior of coarse-grained materials (Babic et al., 2000; LCPC and SETRA, 2000; Naeini and Baziar, 2004; Uthus et al., 2005; Cabalar, 2008, 2011; Duong et al., 2013 and Ho et al., 2014). It can be stated that obviously the increase of the water content produces an increase in the permanent deformation. It has been also observed that, if the percentage of fines is not too large (lower than a critical value), the applied stress is supported by the skeleton of coarse grains. On the contrary, when the percentage of fine is large (higher than a critical value), the fine particles take the main role and isolate the coarse grains. As the results, the soil behavior changes completely (Dash et al., 2010 and Chang et al., 2012). 
The influence of fine content and water content on permanent deformation behavior together has been seldom studied. In this context, an empirical-analytical model was proposed to estimate the permanent deformation of granular materials which takes into account the water content, the fine content, the number of cycles and the stress state. The permanent deformation behavior of Missillac sand was initially determined by the proposed model. Finally, other existing experimental results were used to evaluate the simulation capacity of the proposed model.

\section{PROPOSED EMPIRICAL-ANALYTICAL MODEL}

In this section, we propose an empirical-analytical model taking into account the effects of the water content, the fine content, the number of cycles, and the stress state on permanent deformation of granular materials.

Hornych et al. (1993) proposed the following equation for the permanent axial deformation of the Repeated Load Triaxial Tests (RLTTs):

$$
\varepsilon_{1}^{p^{*}}=A \cdot\left(1-\left(\frac{N}{N_{0}}\right)^{B}\right)
$$

where, $\varepsilon_{1}^{p^{*}}$ is the permanent deformation after $N_{0}$ cycles; $N_{0}$ is the number of cycles before the first measurement; $N$ is the number of cycles; $A$ and $B$ are constant parameters.

Gidel et al. (2001) modified the previous equation to consider the effect of the stress state:

$$
\varepsilon_{1}^{p^{*}}=\varepsilon_{1}^{p 0} \cdot\left(1-\left(\frac{N}{N_{0}}\right)^{-C}\right) \cdot\left(\frac{l_{\max }}{p_{a}}\right)^{n} \cdot \frac{1}{m+\frac{s}{p_{\max }}-\frac{q_{\max }}{p_{\max }}}
$$

where, $l_{\max }=\sqrt{p_{\max }^{2}+q_{\max }^{2}} ; p_{\max }$ and $q_{\max }$ are the largest mean stress and the largest deviatoric stress respectively per load cycle; $\varepsilon_{1}^{p 0}, C, n, m, s$ are constant parameters; $P_{a}=100 \mathrm{kPa}$.

We proposed the two following equations for single-stage RLTTs and multi-stage RLTTs respectively:

$$
\begin{gathered}
\varepsilon_{1}^{p^{*}}=\varepsilon_{1}^{\mathrm{p} 0} \cdot\left(\frac{\omega}{v}\right)^{o \cdot(c c)^{u}}\left(1-\left(\frac{N}{N_{0}}\right)^{\left(b \cdot\left(\left(\frac{v^{\prime}}{\omega}\right)+o^{\prime} \cdot c c+u^{\prime}\right)\right)}\right) \\
\varepsilon_{1}^{p^{*}}=A \cdot\left(1-\left(\frac{N}{N_{0}}\right)^{\left(b \cdot\left(\left(\frac{v^{\prime}}{\omega}\right)+o^{\prime} \cdot c c+u^{\prime}\right)\right)}\right) \cdot\left(\frac{l_{\text {max }}}{p_{a}}\right)^{n} \cdot \frac{\varepsilon_{1}^{p 0} \cdot\left(\frac{\omega}{v}\right)^{o \cdot(c c)^{u}}}{m+\frac{s}{p_{\text {max }}}-\frac{q_{\max }}{p_{\max }}}=f(N) \cdot g\left(q_{\max }\right)
\end{gathered}
$$

Where, $\omega$ is the water content; $c c$ is the fine content; $b, v^{\prime}, o^{\prime}, u^{\prime}, v, o$ and $u$ are constant parameters. 


\section{APPLICATION OF THE PROPOSED MODEL ON PERMANENT DEFORMATION OF MISSILLAC SAND}

The studied material is the Missillac fine sand which is sensitive to moisture. The particle size varies between $0 \mathrm{~mm}$ and $4 \mathrm{~mm}$. In this study, the natural samples contain four different fine contents (passing through the sieve $80 \mu \mathrm{m}$ ):

- M1.3 samples with the fine content which is smaller than $4.0 \%$.

- $\quad$ M4.0 samples with $4.0 \%$ of fine content.

- $\quad$ M7.5 samples with $7.5 \%$ of fine content.

- $\quad$ M15.3 samples with $15.3 \%$ of fine content.

The RLTTs were used to determine the permanent deformation behavior of M1.3, M4.0, M7.5 and M15.3. The samples were prepared in a range of water content between $7 \%$ and $11 \%$ and a dry density of $2.0 \mathrm{Mg} / \mathrm{m}^{3}$.

\section{Single-stage tests}

For the single stage tests, the sample is subjected to $10^{4}$ loading cycles at a frequency of $0.5 \mathrm{~Hz}$ on the constant stress path of $\Delta \mathrm{q} / \Delta \mathrm{p}=3$ with the stress level of $\Delta \mathrm{q}$ $=70 \mathrm{kPa}$ and $\Delta \mathrm{p}=23.33 \mathrm{kPa}$. Because of a different stress path, the permanent axial deformation of M7.5 will not be compared with the other results in this part.

The permanent axial deformation increases with the increase of number of cycles for M1.3, M4.0 and M15.3, for different water contents as illustrated in Fig.1. Fig.2 shows also the variation of the maximum permanent axial deformation with the water content.

Based on these results, it can be observed that at a given condition, the higher the water content, the larger the permanent axial deformation. However, the influence of the fine content is relatively complex: in the case of water contents of $7 \%$ and $8 \%$, the permanent axial deformation of M1.3 are the highest, indicating that the lower the fine content, the higher the permanent axial deformation. Close to the saturated state (water content of $12 \%$ approximately for all of the samples), the effect of fine content is inversed: the soil with the highest fine content (M15.3) exhibits the highest permanent axial deformation.

This phenomenon could be explained as follows: In unsaturated state, the fine content influences the matrix suction significantly. The matrix suction increases with the increasing the fine content, which makes soil particles closer. As the result, soil is more resistant to deformation. On the contrary, close to saturated state, the suction value is almost zero. Moreover, based on the blue value results, we can say the fine particles of Missillac sand are mainly clay, which are sensitive to water and decrease the resistance of soil after combination with amount of water. Similar observations are reported by Huang et al.(2009), Cerni et al.(2012) and Duong et al., (2013). 


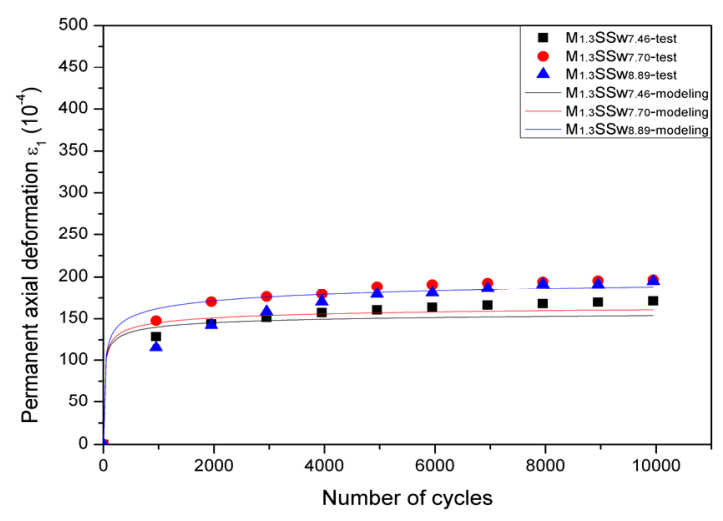

(a)

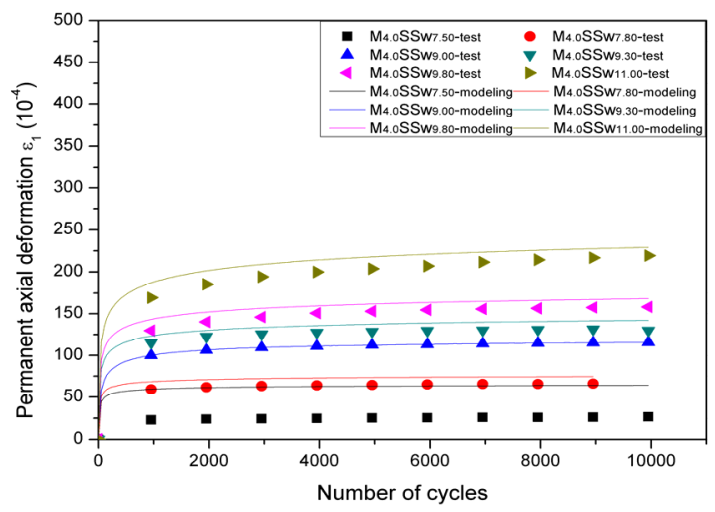

(b)

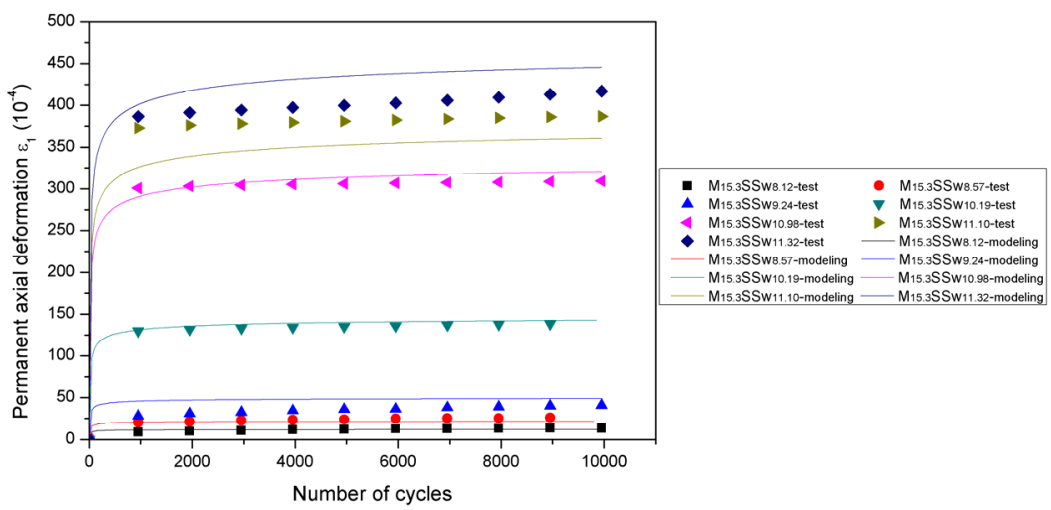

(c)

FIG. 1. Test results as well as model for $\varepsilon_{1}^{p^{*}}$ in single-stage tests, a) M1.3; b) M4.0 and c) M15.3.

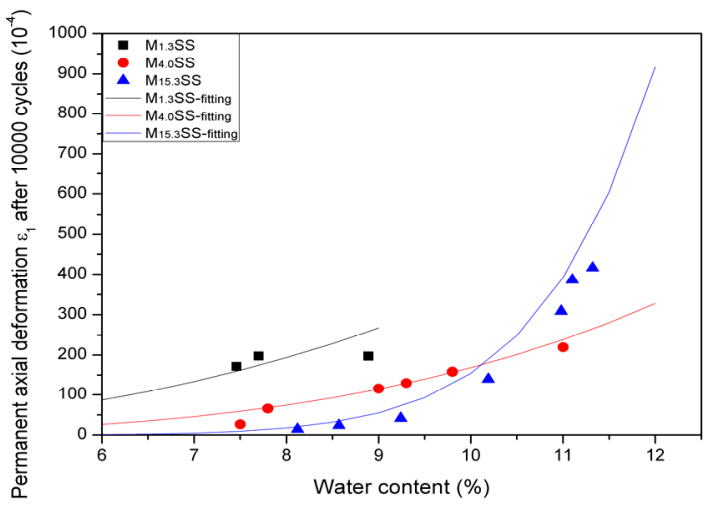

FIG. 2. The maximum permanent axial deformation versus water content in single-stage tests for M1.3, M4.0 and M15.3

Fig.1 shows the comparison between the proposed model for $\varepsilon_{1}^{p^{*}}$ and the experimental results (Eq.3). Generally, it can be stated that the proposed model fits 
well with the experimental results. The parameters of the proposed model were also summarized in Table.1.

Table 1. Fitted parameters of the model for single-stage tests of Missillac sand

\begin{tabular}{|c|c|c|c|c|c|}
\hline \multirow{4}{*}{$\begin{array}{c}\text { Missillac } \\
\text { sand }\end{array}$} & $\varepsilon_{1}^{\mathrm{p} 0}$ & $v$ & $o$ & $u$ & \multirow{2}{*}{ R-value } \\
\cline { 2 - 5 } & 360.564 & 11.000 & 1.637 & 0.705 & \\
\cline { 2 - 5 } & $b$ & $v^{\prime}$ & $o^{\prime}$ & $u^{\prime}$ & \multirow{2}{*}{0.97} \\
\cline { 2 - 5 } & 0.002 & -2501.274 & -7.257 & 195.774 & \\
\hline
\end{tabular}

\section{Multi-stage tests}

Fig. 3 and Fig.4 present the permanent axial deformation versus the number of cycles and stress levels in multi-stage tests for M7.5 and M15.3 respectively. It implies that the evolution of the permanent axial deformation is also related to the stress state: the higher the stress path or the higher the stress level, the larger the permanent axial deformation. Comparing the result of M7.5MS-4 with M15.3MS-4, it can also be observed that the sample close to its saturated state exhibits less mechanical resistance with a higher fine content.

To simulate the multi-stage tests, the parameters of the proposed model were determined by following the next two steps:

- Step 1: Fitting the cumulated permanent axial deformation obtained at the end of each loading stage as shown in Fig.3(b) and Fig.4(b) (representing the $\mathrm{g}\left(\mathrm{q}_{\max }\right)$ part of proposed model in Eq.4);

- Step 2: Fitting the permanent axial deformation evolution with the number of cycles (representing the $\mathrm{f}(\mathrm{N})$ part of proposed model in Eq.4).

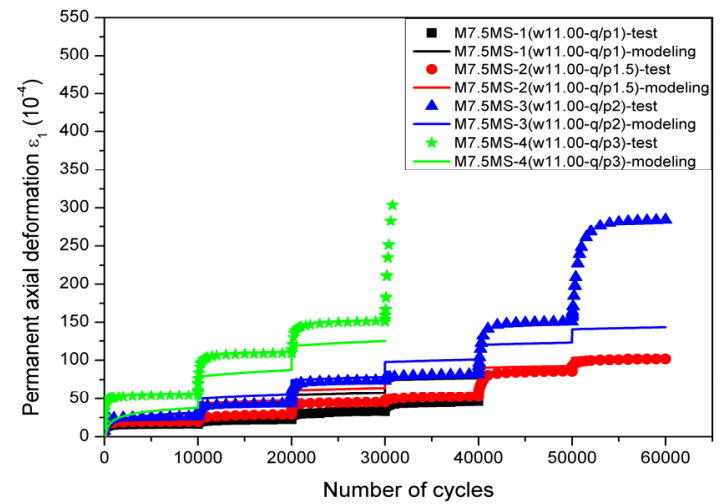

(a)

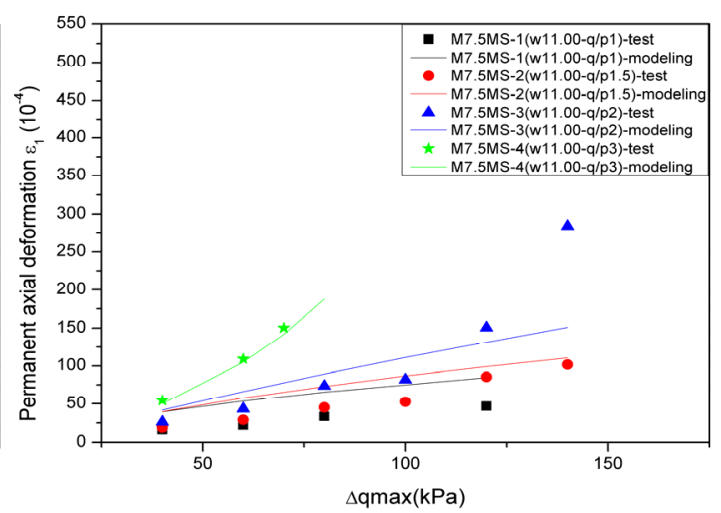

(b)

FIG. 3. Test results as well as model for $\varepsilon_{1}^{p^{*}}$ in multi-stage tests for $M 7.5$ a) Variation of the permanent axial deformation with the number of cycles b) Cumulated permanent axial deformation at the end of each loading stage (The following a) and b) are same as above) 


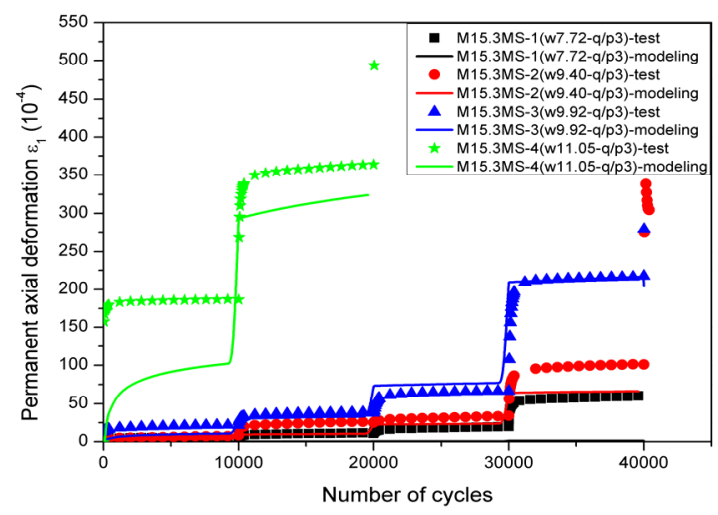

(a)

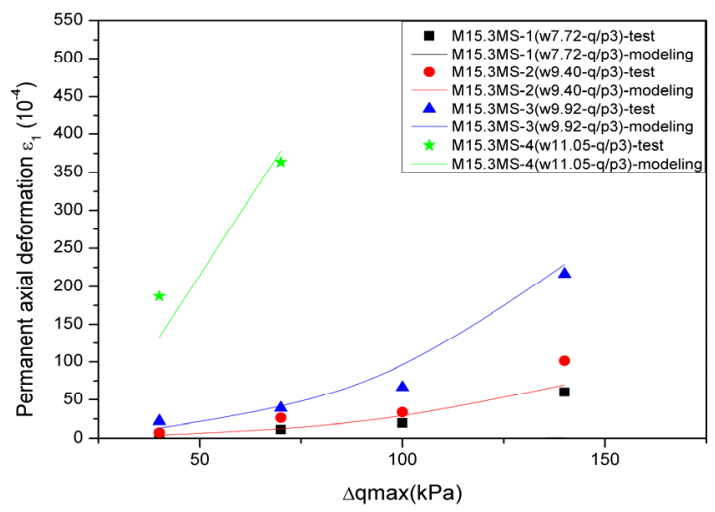

(b)

FIG. 4. Test results as well as model for $\varepsilon_{1}^{p^{*}}$ in multi-stage tests for M15.3

All these parameters were summarized in Table. 2 and the simulation results were presented in Fig.3(a) and Fig.4(a). The results show a good capacity of model to estimate the permanent axial deformation behavior for Missillac sand.

Table 2. Fitted parameters for the model in multi-stage tests of Missillac sand

\begin{tabular}{|c|c|c|c|c|c|c|c|}
\hline \multirow{4}{*}{$\begin{array}{c}\text { Missillac } \\
\text { sand }\end{array}$} & $\varepsilon_{1}^{\mathrm{p} 0}$ & $v$ & $o$ & $u$ & $m$ & $s$ & \multirow{2}{*}{$\begin{array}{c}\text { R- } \\
\text { value }\end{array}$} \\
\cline { 2 - 8 } & 51.111 & 10.140 & 1.377 & 1.003 & 2.620 & 25.693 & value \\
\cline { 2 - 7 } & $n$ & $A$ & $v^{\prime}$ & $o^{\prime}$ & $u^{\prime}$ & $b$ & \multirow{2}{*}{0.86} \\
\cline { 2 - 7 } & 0.500 & 1.776 & -2501.274 & -7.257 & -1069.977 & $8.845 \mathrm{E}-05$ & \\
\hline
\end{tabular}

\section{APPLICATION OF THE PROPOSED MODEL ON PERMANENT DEFORMATION OF THE MATERIAL FROM LITERATURE}

Duong et al., (2013) applied multi-stage cyclic triaxial tests on an interlayer soil used in ancient railway sub-structure in France. These tests were performed at a stress path $(\Delta \mathrm{q} / \Delta \mathrm{p}=3)$, at three different water contents $(4 \%, 6 \%$ and $12 \%)$ and at three different fine contents $(7 \%, 15 \%$ and $23 \%)$.

The test results were shown in Fig.5, Fig.6 and Fig.7, which implied that in unsaturated state and for the same water content, increasing fine content makes the suction higher and thus strengthening the soil. On the contrary, in saturated state, suction becomes zero and the shear strength decreases accordingly. The same results were previously observed for the Missillac sand.

The same procedure was used to simulate the permanent axial deformation of the studied soils during the multi-stage tests. The results are also shown in Fig.5(a), Fig.6(a) and Fig.7(a). Table.3 presents also the fitted parameters of the proposed model. It can be stated that the proposed model performs well. 


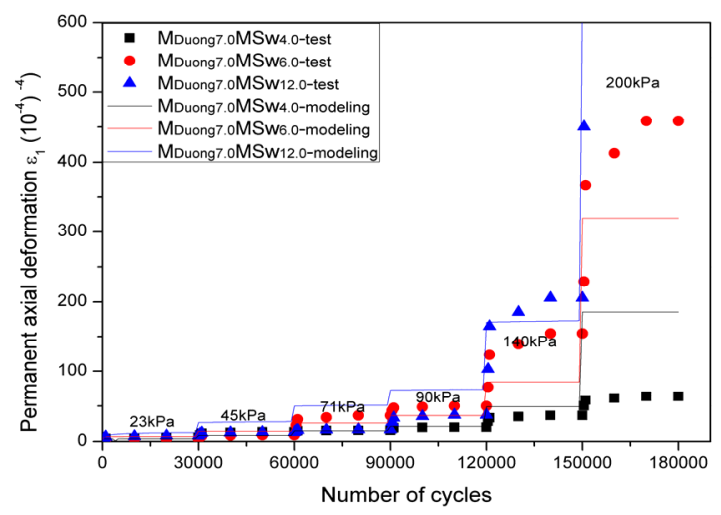

(a)

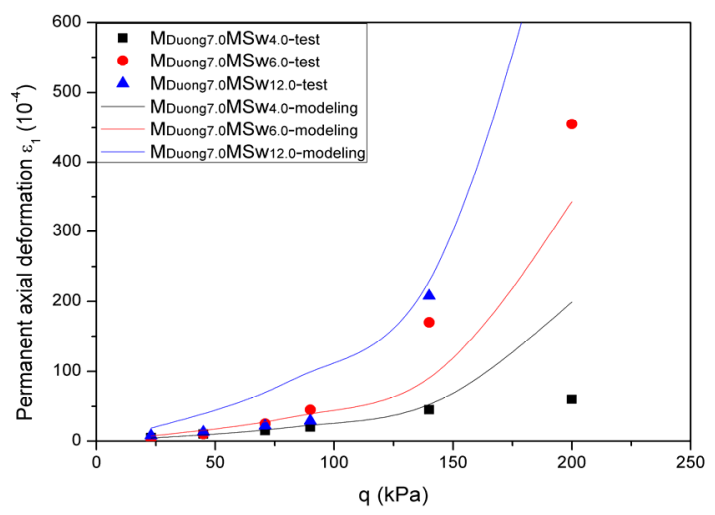

(b)

FIG. 5. Test results as well as model for $\varepsilon_{1}^{p^{*}}$ for MDuong7.0

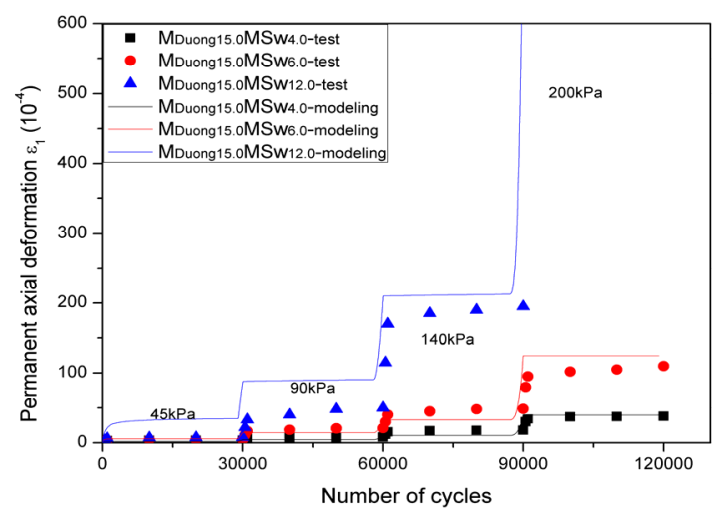

(a)

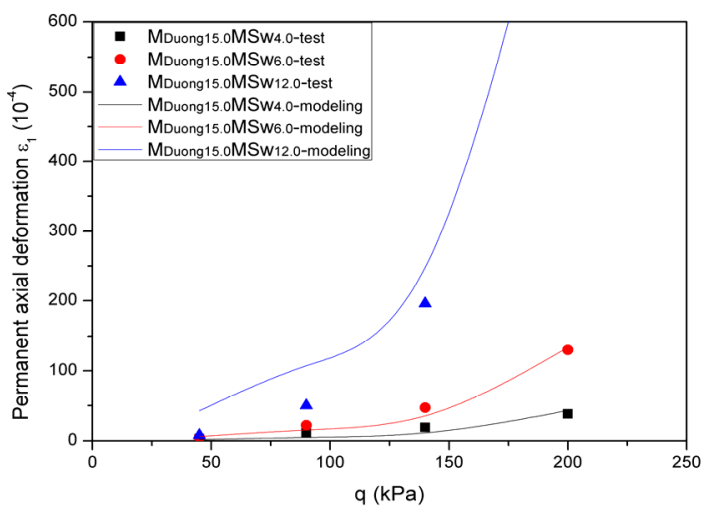

(b)

FIG. 6. Test results as well as model for $\varepsilon_{1}^{p^{*}}$ for MDuong15.0

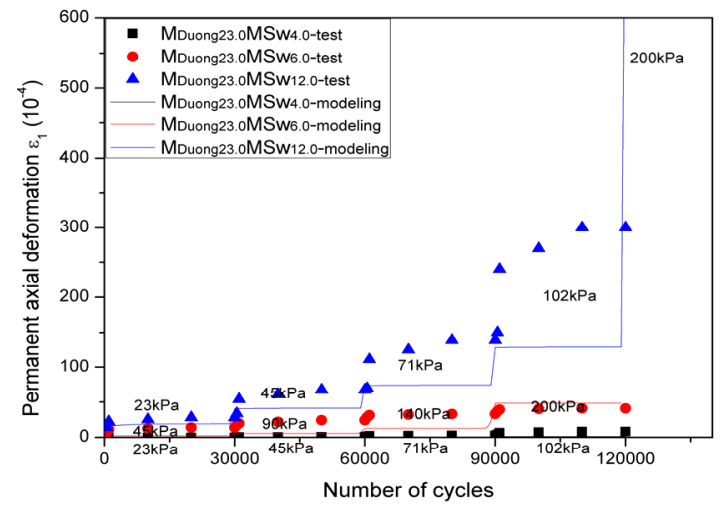

(a)

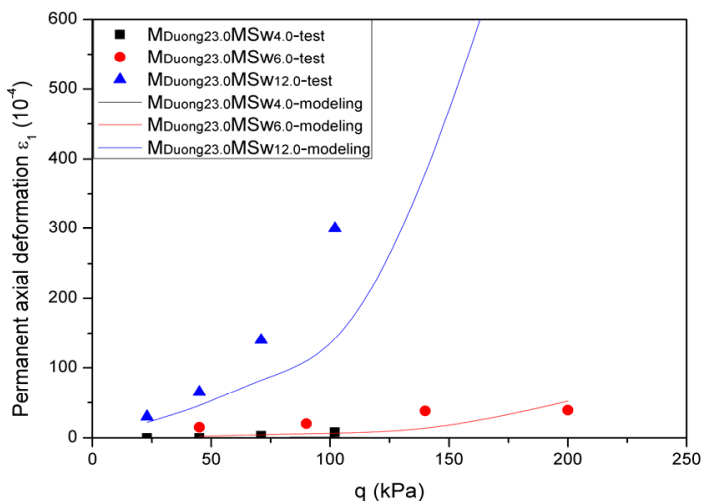

(b)

FIG. 7. Test results as well as model for $\varepsilon_{1}^{p^{*}}$ for MDuong23.0 
Table 3. Fitted parameters for the model in multi-stage tests of interlayer soil

\begin{tabular}{|c|c|c|c|c|c|c|c|}
\hline \multirow{4}{*}{$\begin{array}{c}\text { Interlayer } \\
\text { soil }\end{array}$} & $\varepsilon_{1}^{\mathrm{p} 0}$ & $v$ & $o$ & $u$ & $m$ & $s$ & \multirow{2}{*}{ R-value } \\
\cline { 2 - 8 } & 71.540 & 11.393 & 0.191 & 0.992 & 2.535 & 38.389 & \\
\cline { 2 - 7 } & $n$ & $A$ & $v^{\prime}$ & $o^{\prime}$ & $u^{\prime}$ & $b$ & \multirow{2}{*}{0.96} \\
\cline { 2 - 7 } & 0.301 & 0.931 & -2562.278 & -2.969 & 198.040 & 0.006 & \\
\hline
\end{tabular}

\section{CONCLUSIONS}

The RLTT experimental results show that the permanent axial deformation increases with the increase of the water content, the stress path and the stress level at given conditions. The influence of fine content depends on the initial water content and the water sensitivity of fine particles.

To simulate the permanent deformation of granular materials, this work proposed a new empirical-analytical model taking into account the effect of the water content, the fine content, the number of cycles, and the stress state.

The model was also used to simulate the existing experimental results for different granular materials. The results show a good capacity of the proposed model. These findings reduce the number of tests necessary to determine the soil permanent deformation.

\section{ACKNOWLEDGMENTS}

This work is supported by the China Scholarship Council. Acknowledgments to the previous work of Pierre Hornych (IFSTTAR) and Xuan Nam Ho (INSA-Strasbourg).

\section{REFERENCES}

NF EN 13286-7. (2004). "Mélanges avec ou sans liant hydraulique. Essai triaxial sous charge cyclique pour mélanges sans liant hydraulique."

Babic, B., Prager, A. and Rukavina, T. (2000). "Effect of fine particles on some characteristics of granular base courses." Mater.Struct., Vol. 33 (7): 419-424.

Cabalar, A. (2008). "Effect of fines content on the behavior of mixed specimens of a sand. " Electron.J.Geotech.Eng., Vol. 13 (D): 1-11.

Cabalar, A. (2011). "The effects of fines on the behavior of a sand mixture." Geotech. Geol.Eng., Vol. 29 (1): 91-100.

Cerni, G., Cardone, F., Virgili, A., et al. (2012). "Characterisation of permanent deformation behaviour of unbound granular materials under repeated triaxial loading." Construction and Building Materials., Vol. 28 (1): 79-87

Chang, D.S., Zhang, L. and Xu, T.H. (2012). "Laboratory Investigation of Initiation and Development of Internal Erosion in Soils under Complex Stress States." Proc 6th Conf. on Scour and Erosion, Paris: 895-902.

Dash, H.K., Sitharam, T.G. and Baudet, B.A. (2010). "Influence of non plastic fines on the response of a silty sand to cyclic loading." Soil Found., Vol. 50: 695-704. 
Duong, T.V., Tang, A.M., Cui, Y.J., et al. (2013). "Effects of fines and water contents on the mechanical behavior of interlayer soil in ancient railway sub-structure." Soils and Foundations., Vol. 53 (6): 868-878.

Gidel, G., Hornych, P., Chauvin, J.J., et al. (2001). "A new approach for investigating the permanent deformation behavior of unbound granular material using the Repeated Load Triaxial Apparatus." Bull. Liaison Lab. Ponts Chaussées., Vol. 233: 5-21.

Hornych, P., Corte, J.F. and Paute, J.L. (1993). "Etude des déformations permanentes sous chargement répétés de trois graves non traitées." Bull. Liaison Lab. Ponts Chaussées., Vol. 184: 45-55.

Ho, X.N., Nowamooz, H., Chazallon, C., et al. (2014). "Influence of fine content and water content on the resilient behavior of a natural compacted sand." Road Materials and Pavement Design., Vol. 15 (3): 606-621.

Huang, H., Tutumluer, E. and Dombrow, W. (2009). "Laboratory characterization of fouled railroad ballast behavior." J. Transp. Res. Board., Vol. 2117 (1): 93-101.

LCPC, SETRA, 2000. Technical Guidelines on Embankment and Capping Layers Construction, GTR.

Naeini, S. and Baziar, M. (2004). "Effectof fines content on steady-state strength of mixed and layered specimen sofa sand." Soil Dyn. Earthq. Eng., Vol. 24 (3): 181187.

Uthus, L., Hoff, I., Horvli, I., et al. (2005). "A study on the influence of water and fines on the deformation properties of unbound aggregates." In Bearing capacaity of roads, railways and airfields. Trondheim, Norway. 